\title{
Knowledge, attitudes and practices among grade medical officers of District General Hospital Matara on circulars issued by Ministry of Health, Sri Lanka.
}

Perera KYD, Amadoru SDS, Dileka WSC, Karunaratne HMAH, Dissanayake Y.

\begin{abstract}
Introduction: Circulars help official communications from higher authority to operational level. Government circulars issued by the Ministry of Health $(\mathrm{MOH})$ and other institutions affect the Medical Officers (MOs) in numerous ways and serve multiple purposes.
\end{abstract}

Objective: To assess the knowledge, attitude and practices (KAP) among MOs of District General Hospital (DGH), Matara on circulars issued by $\mathrm{MOH}$.

Methodology: This descriptive cross-sectional study was carried out at DGH, Matara by interviewing 216 MOs using a self-administered questionnaire. Data were analyzed with regards to proportions. Associations were checked using chi square test.

Results and Discussion: Among 185 respondents, most were grade II MOs $(n=102,55 \%)$ and only $18 \%(n=33)$ had administrative experience. All knew that circulars are issued by $\mathrm{MOH} .95 \%$ knew about the circular on Disturbance, Availability and Transport (DAT) allowance of MOs but only 35\%-62\% knew about other circulars. Majority accepted that circulars are important for better administration (85\%) and medical practice $(88 \%)$. Only $55 \%(n=102)$ identified the importance of referring circulars frequently. Reasons for referring circulars were mainly related to personal interest. Main perceived barriers for referring circulars were difficulty in accessing $75 \%(n=138)$, lack of interest $61 \%(n=113)$ and difficulty of understanding technical language $44 \%$ $(\mathrm{n}=81)$.

Administrative post experience had a statistically significant association with the level of knowledge $(\mathrm{p}=0.035)$, good attitudes $(\mathrm{p}=0.048)$ and good practices $(\mathrm{p}=0.042)$ while Grade seniority affected positively on KAP of circulars.
Conclusions and Recommendations: Most were aware about the circulars issued by the MOH and majority accessed circulars for personal interest. Good KAP were shown by doctors with administrative experience. Sensitize newly-appointed MOs on use of circulars and increase accessibility is recommended.

\section{Introduction}

Despite of being categorized as a middle income country, the level of achievement in quality of life indices such as Physical Quality of Life Indices (PQLI), Human Development Index (HDI) and International Human Suffering Index (IHSI) of Sri Lanka is far better compared to other South East Asian regional countries with similar per capita income(1).

Currently SL has 1085 government sector curative health care institutions (3) and 338 preventive / community health care institutions under the Medical Officer of Health. The total employees of 123855 in the $\mathrm{MOH}$ are distributed as 66993 in the line ministry and 56852 in the provincial ministry level(2). Among them 17,615 are Medical Officers (MOs) who are deployed in as an all island basis(3)

There should be an efficient way of transferring information on recent changes in morbidity and mortality patterns, recent improvements in screening, diagnosing, and managing patients, changes in organizational structure and improvements and changes in administrative matters taken by the top-level management of $\mathrm{MOH}$ to the Grade MOs(5). Circulars are the most convenient, reliable, legal, cost effective and efficient method of transferring information to the staff to perform their duties at grass root level (5).

Circulars are issued by Ministry of public administration, Treasury, or by Ministry of Health and they can be Administrative or Clinical circulars (Public Health / Curative Health)(5) and disseminating through webbased systems, sending the hard copies to hospital administrators and displaying on the common/ward notice board etc. 
Grade medical officers who work in curative and public health sectors must update their knowledge to be in par with global heath development. However, in SL, most health professionals lack Continuous professional development process other than those who involved in post graduate training programmes(8). There are numerous occasions where medical officers were taken to task for violating rules and regulations defined by the administrative circulars mostly due to their lack of knowledge about the contents. Further, being the government servants who engaged in public service, and engaged in private practice who treat different ages and different conditions they are legally bound to be aware about the new changes within the system(2).

However, no research has been done in Sri Lanka so far about the knowledge, attitude and practices on circulars among the MOs despite the number of circulars issued. Moreover, it is timely to understand the perceived gap in knowledge, attitude and practices owing to various incidents reported in the country to medical administrators. Thus, identifying the existing gap is very important for better service delivery.

\section{Objective}

To evaluate the knowledge, attitudes and practices among grade medical officers of DGH Matara with regard to the circulars issued by $\mathrm{MOH}$.

\section{Methodology}

Descriptive cross-sectional study, carried out in District General Hospital, Matara (DGH Matara) among 216 Grade medical officers selected through systematic sampling belonging to grade I and grade II, and who have completed a minimum 2 years of experience after completing the internship, conducted from February 2018 to August 2018. The Circulars used for this study was issued only by $\mathrm{MOH}$ and were administration related circulars based on their significance to the grade medical officers, issued between 1st of January 2013 and 1 st of August 2017.

Self-administered questionnaire was distributed after obtaining informed written consent. Data analysis was done using SPSS 21 version software and analyzed using descriptive and analytical techniques.

\section{Results}

Out of 216 MOs who were eligible only 185 participated for the study. The response rate was $86 \%$.

\subsection{Socio demographic characteristics of the Medical Officers in DGH Matara}

Table 4. 1 - Distribution of the sample according to the socio demographic characteristics of the sample

\begin{tabular}{lrr}
\hline Characteristic & No. & Percentage $(\%)$ \\
\hline Gender & 102 & 55.1 \\
Male & 83 & 44.9 \\
Female & & \\
\hline Age & 35 & 18.9 \\
$<35$ years & 95 & 51.3 \\
$35-45 y e a r s$ & 55 & 29.8 \\
$>45$ years & & \\
\hline
\end{tabular}

\section{Post Graduate Qualifications}

$\begin{array}{lll}\text { Yes } & 40 & 21.6\end{array}$

\begin{tabular}{lll} 
No & 145 & 78.4 \\
\hline
\end{tabular}

\section{Civil Status}

\begin{tabular}{lrr} 
Single & 25 & 13.5 \\
Married & 148 & 80.0 \\
Separated & 12 & 6.5 \\
\hline Total & $\mathbf{1 8 5}$ & $\mathbf{1 0 0 . 0}$ \\
\hline
\end{tabular}

Table 4. 2 - Distribution of the sample according to the employment related characteristics of the Sample

\begin{tabular}{lcc}
\hline Characteristics & No. & Percentage $(\boldsymbol{\%})$ \\
\hline Working experience at DGH Matara & \\
=<5 years & 102 & 55.1 \\
6-10 years & 49 & 26.5 \\
11-15 years & 34 & 18.4 \\
\hline Working experience as a Medical Officer & \\
=<5 years & 35 & 18.9 \\
6-10 years & 95 & 51.4 \\
11-15 years & 55 & 29.7 \\
Grade Seniority & & \\
Grade 11 MOs & 102 & 55.1 \\
Grade 1 MOs & 83 & 44.9 \\
\hline
\end{tabular}

\section{Working experience in curative sector posts}

\begin{tabular}{lrr}
$=<5$ years & 48 & 25.9 \\
6-10 years & 92 & 49.7 \\
$11-15$ years & 45 & 24.4 \\
\hline \multicolumn{2}{l}{ Private practice engagement } & \\
Yes & 120 & 64.8 \\
No & 65 & 35.2 \\
\hline
\end{tabular}




\begin{tabular}{|c|c|c|}
\hline Characteristics & No. & Percentage $(\%)$ \\
\hline \multicolumn{3}{|c|}{ Administrative post experience } \\
\hline Yes & 18 & 9.7 \\
\hline No & 167 & 90.3 \\
\hline Total & 185 & 100.0 \\
\hline \multicolumn{3}{|c|}{ Working experience in administrative posts } \\
\hline$=<5$ years & 13 & 72.2 \\
\hline $6-10$ years & 04 & 22.2 \\
\hline $11-15$ years & 01 & 5.6 \\
\hline Total & 18 & 100.0 \\
\hline
\end{tabular}

As shown in table 4.2, majority of MOs ( $\mathrm{n}=95,51.4 \%)$ were having 6-10 years of working experience, while $9.7 \%(\mathrm{n}=18)$ were having administrative experience. Majority $(\mathrm{n}=102,55.1 \%)$ were grade two (II) MOs.

\subsection{Knowledge on circulars issued by MOH among the medical officers in DGH Matara.}

Almost all of participants knew that circulars are been issuid by Ministry of Health and 165 (89\%) were aware about the ways of accessing circulars. However, $11 \%(\mathrm{n}=20)$ were unaware about other relevant agencies except $\mathrm{MOH}$, who are issuing circulars relevant to Medical Officers. A statistically significant, better level of awareness was shown by the grade 1 MOs (50/63), $\mathrm{p}=0.004$ and MOs with administrative experience $(13 / 18), p=0.003$. MOs practiced more than 6 years showed better level of awareness $(99 / 150)$ than junior colleagues $(10 / 35)(\mathrm{p}=0.08)$

Figure 4.1: Distribution of the sample according to awareness about selected circulars

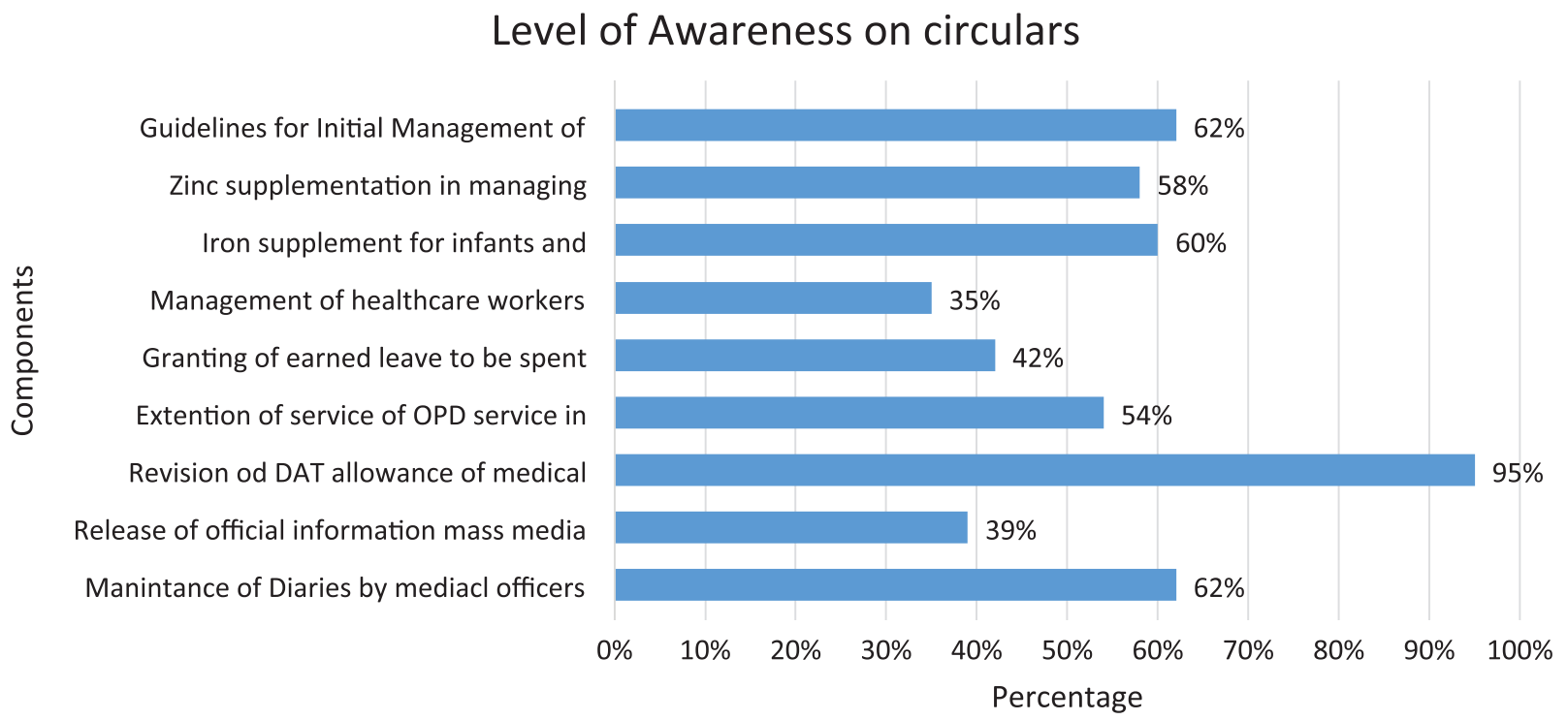

Ninety five percent $(\mathrm{n}=176)$ were aware about the circular on Disturbance, Availability and Transport allowance (DAT) of MOs but only 35\%-62\% knew about other circulars. The senior MOs ( $>6$ years ) showed awareness $(148 / 150)$ than junior doctors $(\mathrm{p}=0.002)$. All the doctors with administrative experience and grade 1 knew about DAT circular. 
4.3 Describing the attitude on using circulars issued by MOH among the medical officers in DGH Matara.

Figure 4.2: Distribution of the sample according to the different attitudes about circulars

\section{Different attitudes about circulars}

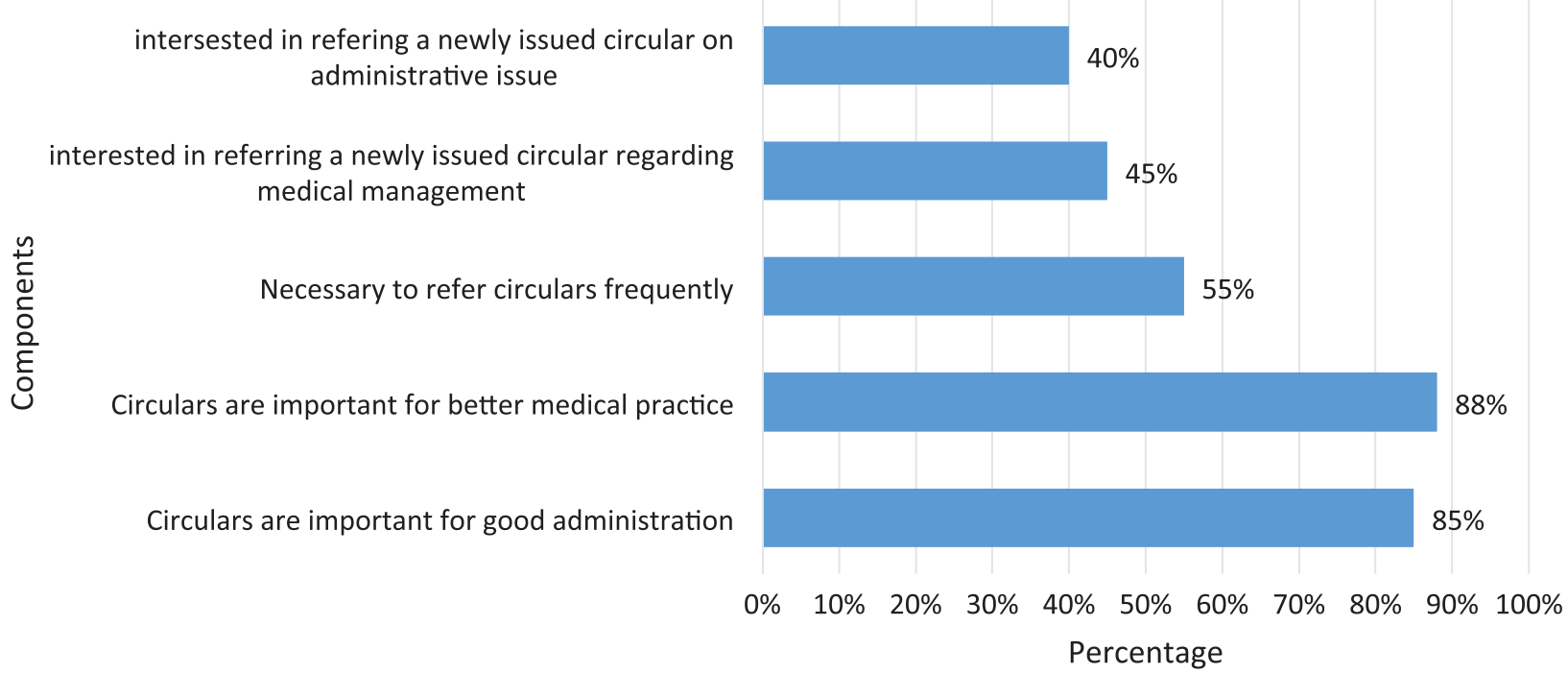

Most held the opinion that circulars are important for better administration $(n=157,85 \%)$ and better medical practice $(n=163,88 \%)$. The medical officers with working experience of more than 11 years $(p=0.004)$ and the MOs with experience in an administrative post $(\mathrm{p}=0.02)$ showed a statistically significant better level of attitudes than others. Working experience or work place did not show a statistically significant difference in better attitudes $(\mathrm{p}>0.05)$. Only $5 \%(\mathrm{n}=102)$ identified the importance of referring circulars frequently $(\mathrm{p}=0.003)$.

4.4 Describing the practices on using the circulars issued by MOH among the medical officers in DGH Matara.

Among the 185 respondents one hundred and fifteen (62\%) referred circulars within past one year of duration. MOs with administrative exposure $(\mathrm{p}=0.04)$, MOs with working experience more than 6 years $(\mathrm{p}=0.02)$, and grade $1 \mathrm{MOs}(\mathrm{p}=0.003)$ had referred the circulars in last year more than the others. Majority (138) accessed electronic copies of the circular while eighty-four (45.4\%) participants accessed both hard copies/notice board and electronic copies to refer the circulars.

For $60 \%$, the main reason for referring circulars were mainly personal interest (eg: salary/allowances). Majority $(n=97,52.9 \%)$ were interested in referring the circulars addressing administrative and clinical management. But, $8(4.4 \%)$ were not interested in any type of circular. Among, the 185 respondents, $84(45.4 \%)$ were actively looking for new circulars.

4.5 Describing the perceived barriers for referring circulars issued by $\mathrm{MOH}$ among the medical officers in DGH Matara.

Main perceived barriers for referring circular were identified as difficulty in accessing $75 \%(\mathrm{n}=138)$ (no computer with internet facility to unit and busy schedule prevents from referring circulars), lack of interest $61 \%(n=113)$ and difficulty of understanding technical language used $44 \%(n=81)$.

4.6 Assessing the factors affecting knowledge, attitudes and practice for referring circulars, by Medical Officers in DGH Matara

A statistically significant better level of awareness was shown by The grade $1 \mathrm{MOs}(50 / 63), \mathrm{p}=0.004$ and MOs with administrative experience $(13 / 18),(\mathrm{p}=0.003)$. The medical officers with working experience more than 11 years $(\mathrm{p}=0.004)$ and the MOs with experience in an administrative post $(\mathrm{p}=0.02)$ showed a statistically significant better level of attitudes than others. Working experience or place did not show a statistically significant difference in better attitudes ( $\mathrm{p}>0.05)$. Referring circulars frequently was identified as important by $55 \%(\mathrm{n}=102)$ of MOs with more than 11 years working experience than the MOs with less experience $(\mathrm{p}=0.003)$. Busy schedule had a statistically significant association with engagement of private practice $(85 / 120), \mathrm{p}=0.002$. 


\section{Discussion}

A self-administered questionnaire was developed instead of other study instruments to assess the knowledge among the participants, in order to ensure not to lose any important information regarding the knowledge and to avoid interviewer bias. During the development of the questionnaire its contents were discussed with a Senior Medical administrator and a Consultant Community Physician to ensure content validity and face validity of the questionnaire. Questions were structured paying special attention for the simplicity and to reduce the time required to fill and increase the responsiveness.

Almost all participants knew that circulars were issued by Ministry of Health, among them 165 (89\%) aware about the ways of accessing circulars. However, $11 \%(n=20)$ were unaware about other relevant agencies except $\mathrm{MOH}$, who are issuing circulars relevant to MOs. Only $70 \%$ can correctly identify a circular issued by $\mathrm{MOH}$ from a normal letter issued by $\mathrm{MOH}$. $95 \%$ $(n=176)$ were aware about the circular on Disturbance, Availability and Transport allowance of MOs, but only $35 \%-62 \%$ knew about other circulars.

Most thought that circulars are important for better administration $(\mathrm{n}=157,85 \%)$ and medical practice $(n=163,88 \%)$ while, $55 \%(n=102)$ identified the importance of referring circulars frequently. Among the 185 respondents $115(62 \%)$ referred circulars within past one year. Among them, majority $(n=95,51.4 \%)$ referred the circular issued on Concessions for Motor Vehicle importing. Majority (138) accessed electronic copies of the circular and it was the most favorable method of access. As $60 \%$ of participants responded that their main reason for referring circulars was mainly for personal interest(salary/allowances) while majority $(n=97$, $52.9 \%$ ) were interested on administrative and clinical management circulars.

The main barriers were, $75 \%$ found it difficult to accessing circulars (no computer with internet facility to unit and busy schedule) $61 \%(n=113)$ showed lack of interest and $44 \%(n=81)$ difficulty of understanding technical language.

Grade seniority, and having administrative experience were shown to have significantly affecting the knowledge and attitudes on circulars. DAT circular was a circular showing one of the best level of awareness. Highest awareness was among the senior MOs ( $>6$ years) grade 1 MOs and MOs with administrative background. However, Gender, working experience, place of work did not show significant relationship.
Only 55\%(n=102) identified the importance of referring circulars frequently and majority with more work experience. Among the 185 respondents, 84(45.4\%) were actively looking for new circulars. This was particularly seen among the medical officers with administrative post than others. Overall, It was shown that the MOs with administrative post experience and senior MOs have good knowledge, attitudes and practices with regards to circular use. Increased use of electronic based circulars was evident.

\section{Conclusions and recommendations}

Majority of MOs working in DGH Matara were aware of accessing the circulars. Knowledge on circulars, was different depending on its relevance and impact to them personally, while the knowledge on circulars issued for public health concerns were poor, despite knowing the importance. Majority were aware on the necessity of circulars for better administration and medical practice. Accessing electronic copies was the most favorable method. referring to of institution notice board was also popular among few specially senior MOs. Overall Good KAP were shown by doctors with administrative experience. Majority were not actively accessing the circulars and main perceived barriers were identified as institutional constraints, personal constraints and system constraints.

Sensitize newly-appointed MOs on the use of circulars and increase accessibility while communicating the major concerns in the administrative and clinical related circulars at the monthly institutional meeting are the method that can be used to increase the MOs awareness on it. Clearly detailed and updated e- versions of the circulars should be available to every Medical Officer. Further studies with MOs in other areas of the country must be carried out to assess the awareness, attitude and practice about the circulars.

\section{References}

1. Fund I monitory. International monetary fund: Sri Lanka [Internet]. 2015. Available from: http:// www.imf.org/en/Countries/LKA

2. Secretariat P. THE CONSTITUTION OF THE DEMOCRATIC SOCIALIST REPUBLIC OF SRI LANKA [Internet]. Department of government printing; 2015. Available from: https://www. parliament.lk/files/pdf/constitution.pdf\%0A

3. Sri Lanka Department of Health. Annual health bulletin 2015. Annual Health Bulletin Srilanka. 2017. 35-36 p. 
4. Ministry of health SL. Annual Health Bulletin 2014.

5. What is circular letter? Importance or advantages of circular letter [Internet]. [cited 2017 Oct 20]. Available from: https://thebusinesscommunication. com/what-is-circular-letter-importance-oradvantages-of-circular-letter/

6. Yates J. Control through communication: the rise of system in American management. [Internet]. Baltimore: Johns Hopkins University Press; 1951. Available from: http://hdl.handle.net/2027/ heb.01161.0001.001.

7. GMOA Good Intern programme. Awareness of preinterns on administrative issues of Department of Health. 2013.

8. W.D.C.U Dias. Knowledge of public service among medical officers. 2011. 